\title{
¿Qué deber saber un médico sobre el ébola?
}

\author{
What a physician must know about Ebola virus?
}

\author{
Pablo Baltar, Benito Regueiro. \\ Servicio de Microbioloxia. Complexo Universitario Hospitalario de Santiago. SERGAS. Santiago de Compostela
}

\section{Introducción}

El reciente brote provocado por el virus Ébola en varios países del oeste africano (Guinea, Liberia, Sierra Leona y Nigeria), se ha traducido, según el último informe de la Organización mundial de la Salud (OMS), en 13.567 infectados y 4.951 fallecidos, cifra que se cree, está subestimada debido a los inexistentes sistemas de sanitarios disponibles en los países centro de la epidemia. Con una mortalidad cercana al $40 \%$ ha supuesto una gran preocupación para todos servicios de salud pública mundiales, especialmente, una vez que se ha tenido conocimiento de los primeros casos en los países desarrollados.

El virus Ébola fue aislado por primera vez en 1976 y debe su nombre al río que pasaba cerca del país donde se localizó el primer brote, la actual República Democrática del Congo, desde entonces se han contabilizado más de 20 brotes. El actual ha estado afectando a África desde, aproximadamente, diciembre de 2013 teniendo constancia de los primeros casos en el sur de Guinea-Conakry aunque no se identificó hasta el mes de marzo de 20141 , lo que ha facilitado la transmisión del virus por la mejora de las comunicaciones entre los países centro de la epidemia². Esta cepa de virus Ébola está fuertemente relacionada con la que está en circulación en África Central desde hace más de 10 años 3 .

La OMS declaró la epidemia de Ébola en África occidental una Emergencia en Salud Pública Internacionalel 8 de agosto de $2014^{4}$.

\section{El virus}

El agente causal de la enfermedad por virus ébola (EVE) es un virus RNA de la familia Filoviridiae y tres grupos Ebolavirus, Marburg y la cepa recientemente descrita por A. Negredo et al del Instituto Carlos III de Madrid los Cuevavirus. Seis cepas diferentes de Ebolavirus han sido identificadas; ebolavirus Zaire (EBOV), ebolavirus Sudán (SUDV), ebolavirus Tai Forest (TAFV), ebolavirus Bundibugyo (BDBV) y ebolavirus Reston (RESTV) 5 . La gran mayoría de los últimos brotes de Ébola en seres humanos han sido vinculados a tres cepas de Ébola: EBOV, SUDV y BDBV6.
El virus del Ébola, EBOV, es la cepa más mortal de las cinco cepas de virus Ébola y corresponde a la que está actualmente en circulación.

Los Filoviridiae tienen forma filamentosa, una envuelta lipídica y contiene un RNA de sentido negativo. El genoma viral codifica una nucleoproteína (NP), la glucoproteína (GP), la ARN polimerasa dependiente de ARN $(L)$, y cuatro proteínas estructurales denominados VP24, VP30, VP35 y VP40. Además, el virus Ébola es capaz de expresar una forma soluble de sGP a través del ARN (Figura 1 $)^{7}$. Representa un agente infeccioso, no un ser vivo y el recuerdo de un modelo de conservación de la información genética muy anterior a nuestro propio origen y lo que le ha permitido llegar a producir el daño que ahora nos causa, es su capacidad de adaptación.

El virus Ébola posee una envuelta lipídica bicapa que sirve como protección al genoma, facilita la entrada en las células hospedadoras y le permite protegerse de la respuesta inmunitaria del organismo ${ }^{8}$.

\section{Reservorio y transmisión}

De las aproximadamente 4.600 especies de mamíferos, 925 son murciélagos. Su origen es el Eoceno hace unos 50 millones de años y casi no han sufrido variaciones. La evidencia de los murciélagos como reservorios para el virus del Ébola proviene de numerosos estudios epidemiológicos y ecológicos. En un estudio realizado en 1996 una amplia gama de hospedadores fueron infectados experimentalmente con el virus del Ébola. Entre ellos, Ios murciélagos destacaron porque fueron infectados, replicaron el virus, y sobrevivieron a la infección ${ }^{9}$. En 2005 Leroy et al. lograron detectar anticuerpos contra el virus del Ébola y ARN de Ébola en tres especies de murciélagos de la fruta: Hypsignathus monstrosus (24\%, 4/17), Epomops franqueti (7\%, 8/117) y Myonycteris torquata $(7 \%, 4 / 58)$. Una de las características de los murciélagos que puede afectar a los virus es el torpor y la hibernación, lo que permite a los virus limitar su agresividad y copiarse en unas condiciones inmejorables.

Figura 1. Estructura del genoma del virus del Ébola.

NP: Nucleoproteína, VP24, 30,35 y 40 son proteínas estructurales, sGP/GP glicoproteínas soluble y de memebrana. L'RNA polimerasa RNA dependiente Fuente: Ansari AA, Clinical features and pathobiology of Ebolavirus infection, Journal of Autoimmunity (2014),

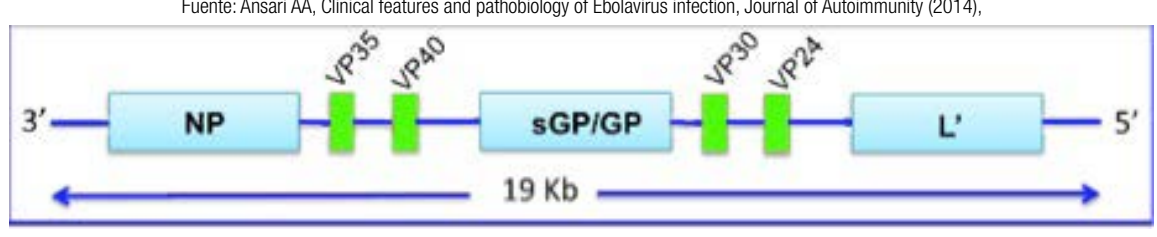


Figura 2. Cascada de eventos patológicos que resulta de la infección severa por EVE.

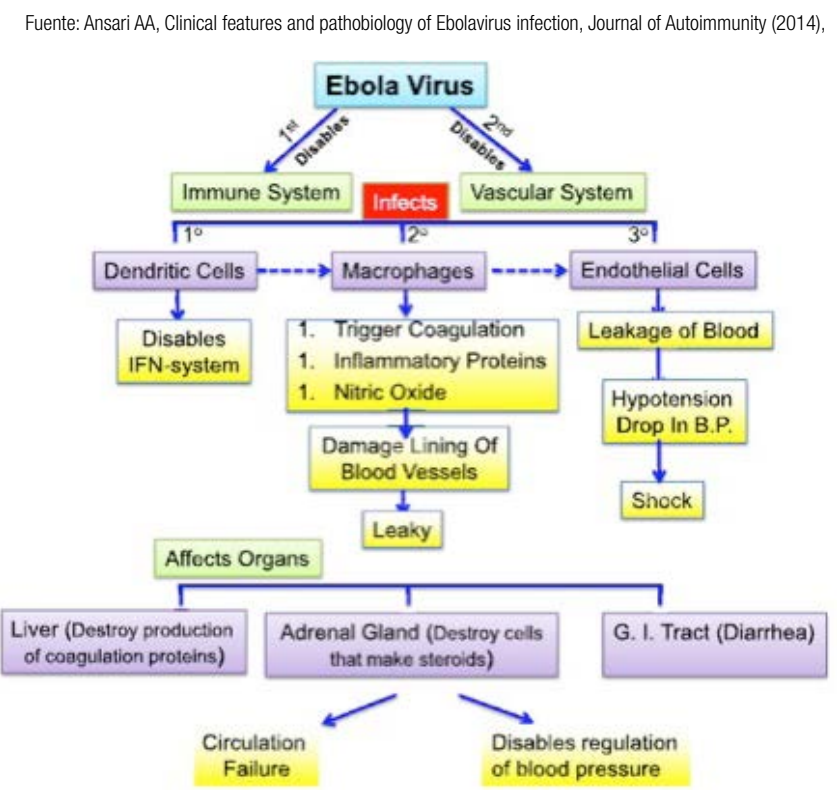

Aunque los primates no humanos han sido una fuente de infección para las personas, se cree que no son el reservorio del virus, sino huéspedes accidentales, como seres humanos ${ }^{10}$.

La transmisión primaria, a pesar de que continúa por confirmarse, considera a los murciélagos fructívoros como los responsables de los inicios de las epidemias y a través de otros animales que como hemos visto, serían huéspedes accidentales pero excelentes transmisores del virus Ébola. La capacidad de estos mamíferos para la emigración (3.800 km/año) les otorga una amplia capacidad de diseminación de la infección. La infecciones por Ébola solían acontecer en zonas rurales remotas con unos índices de fallecimientos muy elevadas con lo que la infección se contenía ${ }^{11}$. En esta epidemia, las cifras que se manejan de infectados y fallecidos sin precedentes ha sido provocada por la elevada movilidad a través de las fronteras ${ }^{3}$, por las infecciones secundarias ligadas al pobre sistema sanitario, la tardanza en el diagnóstico por lo inespecífico de los síntomas iniciales ${ }^{12}$, la pobre estructura sanitaria y de salud pública y los factores socio-culturales que hace que sea habitual tocar a los fallecidos o incluso tenerlos dentro del domicilio conviviendo con los familiares previamente a su entierro ${ }^{1}$.

En los países desarrollados la infección por Ébola la provoca el contacto persona-persona, sobre todo entre el personal sanitario por contacto con órganos, sangre, secreciones u otros fluidos corporales de animales o personas infectadas por contacto directo ${ }^{10}$.

\section{Clínica y patogenia}

El período de incubación transcurre desde 2 a 21 días con un período medio de 7 a 10 días. El problema para el diagnóstico de Ébola es que la clínica inicial que refiere el paciente es muy general e inespecífica pudiendo confundirse con otras patologías virales comunes como la gripe o en países tropicales con malaria 0 dengue. Estos síntomas incluyen fiebre, mialgia, malestar general y en algunos casos escalofríos. El periodo inicial viene seguido de otro período en el que a los síntomas iniciales anteriormente descritos le acompañan molestias gastrointestinales y, en casos severos, erupción maculo-papulosa, petequias, hemorragia conjuntiva, epistaxis, melenas, hematemesis, encefalopatía, shock hipovolémico y muerte ${ }^{13}$.

La inhibición de la respuesta de interferón de tipo I parece ser uno de los aspectos más importantes en la patogénesis de Ébola. Por lo tanto, el virus no solo desactiva la respuesta inmune innata, sino también la humoral adquirida y las respuestas celulares que conducen a la replicación viral y la difusión no controlada (Figura 2) $)^{14}$.

\section{Tratamiento y vacunas}

Varios tratamientos están siendo probados en la actualidad: 1) Como indica S. Garamszegi et al en su publicación de julio de 2014 en PLoS Negl Trop Dis en cuanto al uso de anticoagulantes, el ébola induce la sobreexpresión de factor tisular en los monocitos y macrófagos en primates, y, de dicha sobreexpresión, depende la replicación viral. La sobreexpresión del factor tisular es una de las principales causas de coagulación intravascular y fallo órganico relacionado con la trombosis. Es por ello que las diferentes investigaciones plasmadas en la literatura concluyeron que bloqueando el camino que conduce desde la formación de factor tisular a trombina, se podría alterar la patogénesis de la enfermedad de Ébola. Los dos tratamientos con anticoagulantes utilizados actualmente son, el rNAPC2, proteína anticoagulante derivada, que ha demostrado una eficacia 33\% en el tratamiento en macacos y la Proteína C humana recombinante (rhAPC). Ambas rNAPC2 y rhAPC son los dos únicos anticoagulantes que han sido reportados y que también tienen aportan actividad antiinflamatoria. El rNAPC2 bloquea la activación del factor X por el complejo Vlla. El rhAPC es una serina proteasa que proteolíticamente inactiva el Factor Va y el Factor VIIla. 2) T-750 (favipiravir) es un derivado de la pirazincarboxamida e inhibe la replicación del virus de la gripe. T-750 está siendo probado en la fase clínica, y parece tratar eficazmente la enfermedad del virus del Ébola en ratones. 3) Favipiravir 
se puede convertir a T-705-ribofuranosil- 50 trifosfato, un análogo de nucleótido que puede inhibir la ARN-polimerasa dependiente de ARN 0 inducir mutagénesis letal mediante la incorporación en el ARN viral. 4) BCX-4430, un nuevo análogo de nucleótidos, que inhibe la replicación del virus por al inhibir la función de la ARN polimerasa viral. 5) El suero de los pacientes recuperados también puede ser útil para el tratamiento de EVE. 6) El ZMapp es un cóctel de tres anticuerpos monoclonales de ratón (c13C6, h-13F6, y c6D8). La FDA ha aprobado el uso de ZMapp para el tratamiento de pacientes infectados con el virus Ebola en la actual situación de emergencia ${ }^{15}$.

Kanapathipillai R. et al publican en el NEJM con fecha 7 de octubre que la OMS convocó a una reunión urgente el 29 y 30 de septiembre de 2014 en Ginebra para evaluar los esfuerzos en curso para desarrollar y producir una vacuna eficaz contra el Ébola ${ }^{16}$. Dos vacunas son actualmente candidatas; la CAd3EBOV (cAd3), de GlaxoSmithKline (GSK) y el Instituto Nacional de Alergias Enfermedades Infecciosas de EE.UU. (NIAID); y rVSV $\Delta$ GEBOV-GP (VEVr), de NewLink Genética y la Agencia de Salud Pública de Canadá. Los demás candidatos vacunales están en fases preclínicas anteriores a la de desarrollo. Los estudios de fase 1 estudios de la cAd3 han comenzado ya en EE.UU. y Reino Unido y los investigadores planean comenzar las pruebas para el VEVr pronto. Ambos candidatos vacunales han demostrado el 100\% eficacia en estudios en primates no humanos, pero como se va a traducir esto a humanos no es conocido todavía.

Tanto los gobiernos y las agencias de EE.UU. y Europa han acordado dar todo su apoyo al desarrollo de las vacunas y dar la mayor celeridad a los trámites para la aprobación para el uso de las mismas, siempre y cuando, la seguridad en su uso esté garantizada. En el mejor de los casos, estas vacunas, no estarían disponibles para su uso hasta el primer cuarto de 2015.

\section{Prevención}

En cuanto a su prevención, hay que conocer que el EVE es un problema de salud pública y no un mero problema médico. La medida más importante para la prevención de esta epidemia es su control fronterizo y contener la infección en el lugar de origen. La gran riqueza en materias primas de las zonas afectadas (ricas en petróleo, oro, diamantes, uranio etc.), la mejora de las comunicaciones por carretera y aéreas provoca que la rápida detección e identificación de los posibles pacientes infectados y su puesta en situación de cuarentena sean esenciales para la prevención de una epidemia. Los individuos sospechosos deben ser aislados de forma inmediata e iniciar los cuidados de acuerdo con los protocolos estándar.

Los trabajadores de la salud somos extremadamente susceptibles a contraer EVD de pacientes infectados. El riesgo de infección aumenta a mayor proximidad física con el paciente (se recomienda mantenerse a una distancia de 1,5 metros del paciente) y la frecuencia de aumento de contactos.

Es necesaria poca carga viral para que el contacto pueda ser letal con lo que hay que extremar las precauciones en maniobras críticas como la extracción de sangre de una persona infectada o estar en contacto con sus secreciones, excreciones, tejidos o materiales y residuos del paciente, fase para la que se debería contar con el personal más entrenado y con mayores conocimientos del equipo.

Aunque los aerosoles no se considera que tengan capacidad de transmisión, el personal sanitario ha de ir siempre equipado con los trajes, máscaras, guantes y botas de protección que han de ser impermeables y no han de trabajar con los pacientes infectados más de 20 minutos seguidos ya que para evitar los accidentes es absolutamente básico mantener la máxima concentración en todo momento.

El 23 de septiembre pasado, la prestigiosa revista Science publicó un importante artículo que estudiaba por secuenciación el relativamente simple genoma de 99 virus procedentes de 78 pacientes de Sierra Leona. Este dramático estudio finalizaba recordando "in memoriam" la muerte por ébola de varios de sus autores ${ }^{3}$. Esta publicación ha contribuido a concienciarnos a la comunidad científica y pienso que a las autoridades, la necesidad de parar la epidemia en su origen; una zona rica y poblada de países pobres con condiciones sanitarias deficitarias. Los virus se adaptan y como todo sistema parasitario, tienden a establecer sistemas crónicos que garanticen su futuro; por eso es necesario acabar con el brote lo antes posible limitándolo al mínimo posible, en sus reservorios naturales.

\section{Bibliografía}

1. Baize S, Pannetier D, Oestereich L, Rieger T, Koivogui L, et el. Emergence of Zaire Ebola Virus Disease in Guinea - preliminary report. N Engl J Med, in press

2. World Health Organization: Ebola Virus Disease, West Africa - Update on 27 July 2014. 2014.

3. Gire SK, Goba A, Andersen KG, Sealfon RS, Park DJ, Kanneh L, et al. Genomic surveillance elucidates Ebola virus origin and transmission during the 2014 outbreak. Science 2014, 345:1369-1372.

4. Ebola virus disease update - West Africa, 08 August 2014. 2014.

5. Leroy EM, Kumulungui $B$, Pourrut $X$, Rouquet $P$, Hassanin A, Yaba P, Délicat A, Paweska JT, Gonzalez JP, Swanepoel R: Fruit bats as reservoirs of Ebola virus. Nature 2005, 438:575-576.

6. Briand S, Bertherat E, Cox P, Formenty P, Kieny MP, Myhre JK, Roth C, Shindo N, Dye C: The international Ebola emergency. N Engl J Med 2014, 371:1180-1183.

7. Watt A, Moukambi F, Banadyga L, Groseth A, Callison J, Herwig A, et al. A novel life cycle modeling system for Ebola virus shows a genome length-dependent role of VP24 in virus infectivity. J Virol 2014;88:10511e24.

8. Stahelin RV. Membrane binding and bending in Ebola VP40 assembly and egress. Front Microbiol 2014;5:300.

9. Swanepoel, R.; Smit, S.B.; Rollin, P.E.; Formenty, P.; Leman, P.A.; Kemp, A.; Burt, F.J.; Grobbelaar, A.A.; Croft, J.; Bausch, D.G.; et al. Studies of reservoir hosts for Marburg virus. Emerg. Infect. Dis. 2007, 13, 1847-1851.

10. Enfermedad por el virus del Ebola. Nota descriptiva n. ${ }^{\circ 103}$. Abril de 2014. OMS

11. Chowell G, Nishiura H, Viboud C: Modeling rapidly disseminating infectious disease during mass gatherings. BMC Med 2012, 10:159

12. Khan AS, Tshioko FK, Heymann DL, Le Guenno B, Nabeth $P$, Kerstiëns $B$, Fleerackers $Y$, Kilmarx PH, Rodier GR, Nkuku O, Rollin PE, Sanchez A, Zaki SR, Swanepoel R, Tomori 0 , Nichol ST, Peters CJ, Muyembe-Tamfum JJ, Ksiazek TG: The reemergence of Ebola hemorrhagic fever, Democratic Republic of the Congo, 1995. Commission de Lutte contre les Epidemies a Kikwit. J Infect Dis 1999, 179:S76-S86.

13. Fauci AS. Ebola e underscoring the global disparities in health care resources. N Engl J Med September 18, 2014;371:1084e6.

14. Ansari AA, Clinical features and pathobiology of Ebolavirus infection, Journal of Autoimmunity (2014).

15. Zhong Y, Xu J, Li TS, Yu XZ, Sheng MM. Potential clinical treatment for Ebola pandemic. Sci China Life Sci, 2014, 57: 1-3.

16. Kanapathipillai $R^{1}$, Restrepo AM, Fast P, Wood D, Dye C, Kieny MP, Moorthy V. Ebola Vaccine - An Urgent International Priority. N Engl J Med. 2014 Oct 7. DOl: 10.1056/ NEJMp1412166 